\title{
Modelling the Global Prevalence of COVID-19: An Econometric Approach
}

\section{Wasiu Adekunle ( $\nabla$ wasiu.adekunle@nesgroup.org )}

Nigerian Economic Summit Group (NESG), Lagos, Nigeria https://orcid.org/0000-0003-4968-3642

\section{Feyisayo Oyolola}

Federal University Dutsinma, Katsina State, Nigeria

Oluwafemi A. Atolagbe

University of Lagos, Nigeria

Abdulhameed A. Ademola

University of Lagos, Nigeria

Taiwo H. Odugbemi

University of Abuja

Yusuff O. Ashiru

University of Ibadan, Nigeria

\section{Research Article}

Keywords: COVID-19, global, prevalence, cross-section, quantile regression

Posted Date: February 15th, 2021

DOI: https://doi.org/10.21203/rs.3.rs-241907/v1

License: (c) (i) This work is licensed under a Creative Commons Attribution 4.0 International License.

Read Full License 


\title{
Modelling the Global Prevalence of COVID-19: An Econometric Approach
}

\author{
Wasiu Adekunle ${ }^{1 \#}$, Feyisayo Oyolola ${ }^{2}$, Oluwafemi A. Atolagbe ${ }^{3}$, Abdulhameed A. Ademola ${ }^{4}$, \\ Taiwo H. Odugbemi ${ }^{5} \&$ Yusuff O. Ashiru ${ }^{6}$
}

${ }^{1}$ The Nigerian Economic Summit Group (NESG), Lagos, Nigeria

${ }^{2}$ Federal University Dutsinma, Katsina State, Nigeria

${ }^{3}$ Department of Economics, University of Lagos, Nigeria

${ }^{4}$ Department of Economics, University of Lagos, Nigeria

${ }^{5}$ Department of Economics, University of Abuja, Nigeria

${ }^{6}$ Department of Economics, University of Ibadan, Nigeria

\#Corresponding Author Email: wasiuademola10@gmail.com; wasiu.adekunle@nesgroup.org

\begin{abstract}
Virtually all economies of the world were caught up unawares with the sudden outbreak and rapid spread of coronavirus pandemic from Wuhan City of China to the rest of the world. A number of studies have been conducted to investigate the drivers of the spread of the viral infection. To differ with these studies which were mostly epidemiological-based, we employed a cross-sectional quantile regression approach to uncover both the common and region-specific socio-economic conditions that are instrumental in the spread of the pandemic across four continents of the world including Africa, Asia, America and Europe. Across the four continents, we observed that age characteristics proxied by life expectancy and the size of the aged population, as well as, overall spending on the health sector have significant impact on the spread of COVID-19. We also noted the significant roles of out-of-pocket spending on healthcare in the case of Africa, net migration in the case of America and tourism attraction in the case of Europe in driving the prevalence of coronavirus. We therefore draw policy implications in terms of the need for improved spending on health sector across continents and the need to intensify health checks for travelers and immigrants, and also the need to emphasize regular check-ups for all individuals across continents since current realities have shown that no age-group is spared of contracting the viral infection.
\end{abstract}

Keywords: COVID-19, global, prevalence, cross-section and quantile regression

\section{JEL Classification: B4, C5, I1}

\section{Statement of Conflict of Interest:}

I, Wasiu Adekunle, on behalf of my co-authors declare that "there is no conflict of interest regarding the peer-review of our manuscript titled Modelling the Global Prevalence of COVID19: An Econometric Approach". We received no funding for this particular research. 


\section{Introduction}

COVID-19 is a coronavirus disease that became a global public health emergency after World Health Organization (WHO) declared it a global pandemic on March $11^{\text {th }}$ 2020. Atypical of this strand of virus as confirmed by health specialists is its ability to transmit from one host to another even before the 14-day gestation period, which made it difficult to be easily contained relative to other health crises, such as, Ebola Virus Disease (EVD) outbreak of 2014 and other past viral infections. Examples of these viral infections include the severe acute respiratory syndrome coronavirus (SARS-CoV) outbreak in Guandong, China in 2002; H5N1 influenza, a re-emergence in 2003, H1N1 2009; and the Middle East respiratory syndrome coronavirus (MERSCoV) in Korea. The major targets of these deadly epidemics are the lungs, and as a result, the patients experience acute lung injury and acute respiratory distress syndrome which results in pulmonary failure and fatality (Shereen et al., 2020).

Specifically, at the earlier stage of the COVID-19 outbreak, over $90 \%$ of the cases were reported to have originated from Hubei Province, Wuhan, China in December 2019. However, the increasingly interconnectedness of world nations reinforced the rapid spread of coronavirus from Wuhan City of China. The mode of transmission is basically through person-to-person contacts within and outside of China (Chavez et al., 2020; CDC HAN Archive, 2020; Mcintosh et al., 2020; WHO, 2020a). As of $31^{\text {st }}$ March 2020, the United States, Spain, Italy and the United Kingdom topped the list of countries with the highest number of confirmed cases of COVID-19 in the world (WHO, 2020b). According to the daily case summary by WHO, as at $30^{\text {th }}$ April 2020 , the total number of coronavirus patients and deaths worldwide stood at 3,090,445 and 217,769 respectively. The report (WHO, 2020c) showed that the US accounted for 32.5\% of the number of confirmed cases, followed by Spain (6.9\%), Italy (6.6\%), the UK (5.3\%) and Germany (5.1\%). Correspondingly, these countries had a combined share of $62.9 \%$ in the total number of coronavirus-induced fatalities.

In May $31^{\text {st }} 2020$, the number of global confirmed cases and deaths recorded further rose to $5,934,936$ and 367,166 respectively. Of these cases, US still remains the topmost country with the highest number of confirmed with a share of $28.9 \%$, followed by Brazil with $7.8 \%$, Russia with $6.8 \%$, UK with $4.6 \%$ and Spain with $4 \%$ (WHO, 2020d). The global number of confirmed cases in June 2020 reflect a significant upward surge in the spread of the virus. A total number of $10,185,374$ and 503, 862 confirmed number of cases and deaths respectively were recorded in June $30^{\text {th }} 2020$. The US accounting for $24.9 \%$ of total number of confirmed cases globally ranks topmost on the list of countries cases. The next is Brazil with a share of $13.2 \%$, then Russia with $6.4 \%$, India with 5.6\% and UK with $3.1 \%$ (WHO, 2020e).

More disturbing, however, is the fact that the viral infection has rapidly metamorphosed from a mere health crisis into a global economic crisis. In the first quarter of 2020, statistics showed that the US and China contracted by $4.8 \%$ and $6.8 \%$ respectively. Reports also revealed that Germany and the UK slipped into recession in the same quarter. In its revised World Economic Outlook for 2020 , the IMF reviewed downwards the growth forecasts, in most cases to negative territory, for a number of countries, largely due to the unprecedented contagious effect of coronavirus outbreak. Specifically, the Fund projected that the global economy would contract by $-4.9 \%$ in 2020, while top advanced countries are expected suffer an economic slump, depending on the level of severity of the viral infection in their respective economies. On a country-specific basis, the IMF projected 
that Italy, Spain, the UK, the US and Germany would contract by $-12.8 \%,-12.8 \%,-10.2 \%,-8 \%$ and $-7.8 \%$, respectively, in 2020. From among the top emerging and developing economies (EMDEs), China is expected to record slower economic growth at $1 \%$ while Brazil, South Africa, Saudi Arabia, Russia, Nigeria are projected to contract by $-9.1 \%,-8 \%,-6.8 \%,-6.6 \%$ and $-5.4 \%$, respectively (IMF, 2020).

Given the aforementioned, an important question that comes to mind is: what optimal coping strategies and palliative measures should been put in place by all countries in order to avert coronavirus-induced economic contraction? On a general note, countries have adopted both economic and non-economic coping strategies and measures in order to contain the spread of COVID-19 in their respective domains. The most prominent non-economic strategies are social distancing and lockdown measures. In addition to lockdown restrictions, other recommended noneconomic measures include: wearing of nose mask, regular cleaning of hands with sanitizer, encouraging the public to undergo coronavirus test, self-isolate, as well as, report confirmed cases (Surico and Galeotti, 2020). On the other hand, the provision of fiscal and monetary stimulus packages across countries - advanced and EMDEs - constitute the economic measures directed at moderating the adverse impact of the coronavirus-induced lockdown restrictions on households and businesses, respectively ${ }^{1}$. In order to ensure that the right quantum of economic and noneconomic strategies is put in place by different countries depending on their structural peculiarities, we consider it expedient to investigate into the key factors driving the global prevalence of COVID-19.

To this end, the aim of this study is in three folds. The first is to identify the key factors driving the rapid spread of COVID-19 by considering the socio-economic characteristics of countries sampled from the list of advanced economies and EMDEs. Also, we address the issue of heterogeneity across countries within the same continent by employing the cross-sectional quantile regression approach. Finally, key policy measures that would not only assist in containing the spread of COVID-19, but would also mitigate the adverse impact of the epidemic on world economies would be recommended.

The rest of the paper is structured as follows. Section Two covers materials and methods ranging from a review of the empirical literature, the theoretical framework to methodology and data issues. Section Three is devoted to empirical analysis and discussion of results, while Section Four concludes the study.

\section{Materials and Methods}

\subsection{Review of the Empirical Literature}

Existing literatures on key factors driving the prevalence of COVID-19 and its impact on both local and global economies is rather diverse. For instance, Wang, et al. (2020) employed a crosssectional and panel regression approach to analyze the determinants of coronavirus transmission. From their findings, high temperature and high relative humidity are key factors that influence the transmission of COVID-19. In the same vein, Al-Waeli, et al., (2020), through scrutiny, special and temporal analysis method found climatic factors, particularly low relative humidity and high temperature drive the spread of coronavirus in Iraq. On the other hand, the study of Jindal (2020)

1 Refer to the IMF's Policy Tracker, retrievable via: https://www.imf.org/en/Topics/imf-and-covid19/PolicyResponses-to-COVID-19 
counters this assertion from his findings that environmental temperature has no impact on the spread of COVID-19 as long as the virus is transferred at close proximity because the virus survives well in the human body temperature.

Funk (2010) through a susceptible-infected-removed (SIR) model approach discovered that human behavior significantly influences the spread and control of infectious diseases. From the extant review of literature method, Ludvigsson (2020) observe age characteristic as the most factor determining the spread of coronavirus. The points out that, children have milder coronavirus disease course, better prognosis and extremely rare death to coronavirus than adults. Ding, et al., (2020) employs a descriptive approach and discovers that population migration influences the spread of infectious disease. Employing a multivariable linear regression and binary logistic regression analysis, Zhong, et al. (2020) reports that the spread of coronavirus is critically influenced by level of socioeconomic status, especially women with good knowledge, optimistic attitudes, and appropriate practices.

Barnett-Howell and Mobarak (2020) investigated the varying benefits of social distancing and suppression across rich and poor countries. The study utilized a country specific value of statistical life (VSL) estimates approach on 9 study countries (United States, Brazil, Pakistan, Nigeria Bangladesh, Japan, India, Indonesia, South Africa and Nepal). Their findings assert that the composition of population in rich countries is highly skewed towards the aged; hence, COVID-19 mortality effects are predicted to be much higher in rich countries than in poor countries even after accounting for differences in countries' health system capacity. Similarly, Ozili and Arun (2020) carried out a study on the measures (restrictive, monetary policy, fiscal policy and public health measures) adopted during the COVID-19 pandemic period and the impact of social distancing policies on economic activities and stock market indices. The study observed that restrictions on internal movement and higher fiscal policy spending have positive impact on the level of economic activities regardless of the rising number of confirmed coronavirus cases which has no significant effect on the level of economic activities.

Conversely, Brenton and Chemutai (2020) examined the responses of trade to COVID-19 crises in Africa. The study observed that trade helps to reduce prevalence of coronavirus disease by providing access to essential medical goods and services. The study also pointed out that in ensuring access to food, enhancing nutritional intake to boost the immune systems and ability to resist the virus, providing farmers with necessary inputs for the next harvest and supporting jobs in the face of a global recession reduces tendency for high unemployment and poverty crises. In the same vein, Bloom and Canning (2004) maintains that, international cooperation is key in preventing and containing epidemics. Their finding reveal that strengthening countries heath system helps to fend off disease outbreaks and limit the impact of those that do emerge.

With the aid of lives saved tool, Roberton, et al. (2020) explored the indirect effects of COVID19 pandemic on maternal and child mortality in 118 middle and low income countries. Their findings revealed that disruption of routine health care and decline in the access to food such as the collapse of health system tend to lead to increase the rate of child and maternal deaths. To Meo, et al., (2020), the male gender with age 60 and above have higher rate of infection. Gémes, et al., (2020) utilizing a sensitivity analysis described the prevalence and burden of prognostic factors of severe COVID-19 in Sweden. According to their findings, the burden and prevalence of medical 
condition such as asthma, diabetes and cancer increases as age increases and that that one in every five individuals is at increased risk of severe COVID-19 burden in Sweden. This parallels the findings of Clark (2020), which estimated the number of individuals that may be at increased risk of severe COVID-19 illness due to underlying health conditions at $16 \%$ and $31 \%$ in Africa and Europe, respectively. Through OLS estimation, Ogundokun, et al. (2020) found that travelling history and contacts increase the chances of people being infected with COVID-19 by $85 \%$ and $88 \%$, respectively in Nigeria. This result suggests the need for the government to ensure that the travel and tour agencies have better precautions and preparations in place before re-opening.

Utilizing a time sequence mean weighting technique, Qasim, et al. (2020) observed that countries with poor health facilities and services are at a greater risk of COVID-19 infection compared to other countries with adequate and advanced health facilities. In addition, the study of Muurlink and Taylor-Robinson (2020), identified cultural factors, particularly the extent to which long clothing are worn and the practice of adult separation by gender, to inadvertently influence the rapidity and spread of communicable diseases including COVID-19. Karatayev, Anand, Bauch, (2020) modelled the timing and organizational scale at which workplace and school re-opening strategies can minimize both the number of infections and person-days lost to closures, during the late-stage and early-stage epidemic. They found that local strategy of re-opening/re-closing workplaces and schools county-by-county results in far fewer person-days lost to closure with a slightly higher number of COVID-19 cases, even after allowing for high inter-country travel. The study of Taboe, et al., (2020), found that larger number of asymptomatic COVID-19 infected persons aggravate the spread of coronavirus in West Africa. They asserted early identification and isolation of asymptomatic persons would significantly curtail the spread of COVID-19.

In order to differ from past empirical studies regarding the current subject matter (see, for instance, Brenton and Chemutai, 2020; Ding et al., 2020; Howell and Mobarak, 2020; Lin et al., 2020, Ludvigsson, 2020; Ozili and Arun, 2020; Wang et al., 2020 and Zhong et al., 2020, to mention but few), our paper offers the following innovations. The growing interdependence among global economies makes it difficult for a country to single-handedly contain an epidemic, such as, COVID-19, until it became a global pandemic. While previous studies have identified factors driving the prevalence of epidemics (different forms of viral infections), no study has explicitly captured the underlying characteristics of specific regions and countries. This study seeks to fill this gap by considering the distinct socio-economic characteristics that are peculiar to the two classes of countries, namely, advanced economies and the EMDEs on a continental basis. Another gap in the literature is that the majority of past studies employed descriptive analyses and largely focused on medical and epidemiological perspectives. This study ultimately offers an econometric modelling of the global prevalence of coronavirus in some selected advanced countries and EMDEs. The end-result of our modelling exercise would help to suggest coping strategies that are suitable for each category of countries depending on their individual and regional peculiarities.

\subsection{Theoretical Framework}

This study draws strongly on the model of Knowles and Owen (1995) to derive the determinants of health capital indicators and those of output per-worker. Their model extends the Mankiw, Romer, and Weil (MRW, 1992)'s augmented-Solow model to include health capital as a component of the broad-based human capital. The assumptions underlying the model of Knowles and Owen (1995) are as follows: 
1. The production is of the Cobb-Douglas type that exhibits constant returns in respect of capital, labour, and human capital components (education and health indicators). That is,

$Y_{t}=K_{t}^{\alpha} E_{t}^{\beta} X_{t}^{\psi}\left(A_{t} L_{t}\right)^{1-\alpha-\beta-\psi}$

Where subscript ' $\mathrm{t}$ ' stands for time; $\mathrm{Y}$ is real output; $\mathrm{K}$ is stock of physical capital; $\mathrm{E}$ is stock of educational human capital; $X$ is the stock of health human capital; $L$ is labour input; $A$ is the level of technology; The parameters $\alpha, \beta, \psi$, and $(1-\alpha-\beta-\psi)$ are respectively, the shares of physical capital, education capital, health capital, and effective labour in output, with the restrictions that 0 $<\alpha, \beta, \psi$, and $(1-\alpha-\beta-\psi)<1 ; \alpha, \beta, \psi, \epsilon[0,1] ; \alpha+\beta+\psi<1$

2. In per unit of effective labour terms, the production function becomes

$y_{t}=k_{t}^{\alpha} e_{t}^{\beta} x_{t}^{\psi}$

Where $k_{t}=\frac{K_{t}}{A_{t} L_{t}}, e_{t}=\frac{E_{t}}{A_{t} L_{t}}, x_{t}=\frac{X_{t}}{A_{t} L_{t}}$

3. Labour and technology grows at an exogenous rates, $\mathrm{n}$ and $\mathrm{g}$, respectively, so that labour and technology at period $\mathrm{t}$ are given as

$L_{t}=e^{n t} L_{0} ; A_{t}=e^{g t} A_{0}$

4. The accumulation of physical, educational and health capital can be expressed as

$K \dot{t}=S_{K} Y_{t}-\delta K_{t}$

$E_{t}=s_{E} Y_{t}-\delta E_{t}$

$X_{\dot{t}}=s_{X} Y_{t}-\delta X_{t}$

The dynamics of physical, educational and health capital can be derived as follows:

From eq. (3), differentiating the capital per effective labour with respect to time gives

$\dot{k}_{t}=\frac{\left(A_{t} L_{t}\right) K_{t}-K_{t}\left(A_{t} L_{t}+L_{t} A_{t}\right)}{\left(A_{t} L_{t}\right)^{2}}$

Eq. (3.8) reduces to:

$\frac{\dot{K_{L}}}{A_{i_{L} L_{l}}}-\frac{K_{t}}{A_{\mathrm{f}} L_{i}}\left(\frac{\dot{A_{L}}}{A_{i}}+\frac{\dot{L_{\mathrm{f}}}}{L_{\mathrm{f}}}\right)$

Given that $\dot{K}_{t}=s_{K} Y_{t}-\delta K_{t} ; k_{t}=\frac{K_{t}}{A_{t} L_{t}} ; \frac{A_{t}}{A_{t}}=g ; \frac{L_{t}}{L_{t}}=n ; \frac{Y_{t}}{A_{t} L_{t}}=y_{t}$, Eq. (9) reduces to $k_{t}=s_{k} y_{t}-(n+g+\delta)$

Following the same steps as above, the dynamics of educational and human capital can be obtained, respectively, as follows:

$e_{t}=s_{e} y_{t}-(n+g+\delta)$

$\dot{x_{t}}=s_{x} y_{t}-(n+g+\delta)$

Where $s_{k}, S_{e}$ and $s_{x}$ are the constant proportions of income that are invested in physical, educational and health capital, respectively; $\delta$ is the common depreciation rate;

5. At steady state, $k_{t}=e_{t}=x_{\dot{t}}=0$. Then solving for the steady-state values of physical, education and health capital gives

$0=s_{k} y_{t}-(n+g+\delta) k_{t}^{*}$

$0=s_{E} y_{t}-(n+g+\delta) e_{t}^{*}$ 
$0=s_{X} y_{t}-(n+g+\delta) x_{t}^{*}$

So that

$k_{t}^{*}=\frac{s_{k} y_{t}}{(n+g+\delta)}$

$e_{t}^{+}=\frac{s_{E} y_{t}}{(n+g+\delta)}$

$x_{t}^{*}=\frac{s_{X} y_{t}}{(n+g+\delta)}$

The three equations expressed in per unit of effective labour terms, the steady-state levels of physical, educational and health capital are functions of their respective investment shares of output, depreciation rate, and growth rates in labour and technology.

Eq. (16), eq. (17), and eq. (18) can be solved further to substitute for the value of output per unit of effective labour as follows.

From the three equations, one can find that

$\frac{k_{t}^{*}}{s_{k}}=\frac{e_{t}^{*}}{s_{E}}=\frac{x_{t}^{*}}{s_{X}}=\frac{y_{t}}{(n+g+\delta)}$

So that we have can have the following relations

$k_{t}^{*} s_{E}=e_{t}^{*} s_{k}$

$e_{t}^{*} S_{X}=x_{t}^{*} S_{E}$

$k_{t}^{*} s_{X}=x_{t}^{*} s_{l c}$

Substituting the value of output per unit of effective labour into eq. (16), eq. (17), and eq. (18) and making use of the information from equations (20), (21) and (22).

Recall from eq. (2) that:

$y_{t}=k_{t}^{\alpha} e_{t}^{\beta} x_{t}^{\psi}$

Then we have:

$k_{t}^{*}=\frac{s_{k} k_{t}^{\alpha} e_{t}^{\beta} x_{t}^{\psi}}{(n+g+\delta)}$

$e_{t}^{*}=\frac{s_{E} k_{t}^{\alpha} e_{t}^{\beta} x_{t}^{\psi}}{(n+g+\delta)}$

$x_{t}^{*}=\frac{s_{X} k_{t}^{\alpha} e_{t}^{\beta} x_{L}^{\psi}}{(n+g+\delta)}$

Collecting like terms, the three equations reduce to:

$k_{l}^{1-\alpha}=\frac{s_{k} e_{t}^{\beta} x_{t}^{\psi}}{(n+g+\delta)}$

$e_{t}^{1-\beta}=\frac{s_{E} k_{t}^{\alpha} x_{t}^{\psi}}{(n+g+\delta)}$

$x_{t}^{1-\psi}=\frac{s_{X} k_{t}^{\alpha} e_{t}^{\beta}}{(n+g+\delta)}$

Substituting the values of $k_{t}, e_{t}, x_{t}$ in the three expressions from eq. (26), eq. (27), eq. (28) yields:

$k_{t}^{1-\alpha}=\frac{s_{k}\left(\frac{s_{E^{k}}}{s_{k}}\right)^{\beta}\left(\frac{s^{k} X_{t}}{s_{k}}\right)^{\psi}}{(n+g+\delta)}$ 
$e_{t}^{1-\beta}=\frac{s_{E}\left(\frac{s^{2} e_{t}}{s_{E}}\right)^{\alpha}\left(\frac{s_{X} e_{t}}{s_{E}}\right)^{\psi}}{(n+g+\delta)}$

$x_{t}^{1-\psi}=\frac{s_{X}\left(\frac{s^{x} K_{t}}{s_{X}}\right)^{\alpha}\left(\frac{s_{E} x_{t}}{s_{X}}\right)^{\beta}}{(n+g+\delta)}$

Solving for the values of $k_{t}^{*}, e_{t}^{*}$, and $x_{t}^{*}$ in eq. (29), eq. (30), and eq. (31), respectively, we have:

$k_{t}^{*}=\left[\frac{s_{K}^{1-\beta-\psi} s_{L}^{\beta} s_{X}^{\psi}}{(n+g+\delta)}\right]^{1 / n}$

$e_{t}^{+}=\left[\frac{s_{E}^{1-\alpha-\psi} s_{S}^{\alpha} s_{X}^{\psi}}{(n+g+\delta)}\right]^{1 / n}$

$x_{t}^{\times}=\left[\frac{s_{X}^{1-\alpha-\beta} s_{K}^{\alpha} s_{E}^{\beta}}{(n+g+\delta)}\right]^{1 / n}$

Where $\eta=1-\alpha-\beta-\psi$

Eq. (32), eq. (33), and eq. (34) imply that the determinants of steady-state levels of physical, educational and health capital include the fractions of investment shares of output devoted to the accumulation of physical, educational and health capital (that is, $S_{k}, S_{E}$, and $S_{X}$, respectively), the share of effective labour $\left(A_{t} L_{t}\right)$ in output, depreciation rate, and the growth rates in labour $\left(L_{t}\right)$ and technology $\left(A_{t}\right)$.

Moreover, prevalence of diseases, as a stand-alone variable, does enter into the growth equation (see, eq. 1) directly. It however affects economic growth via its impact on the stock of health human capital of the workforce $\left(x_{t}\right)$. Although no known or settled body of economic theory is devoted to an explanation of the determinants of health capital stock at the macro level, nonetheless, according to McDonalds and Roberts (2006), the next-best approach is to define a reduced-form model of health capital stock.

This reduced-form health capital model postulates that health capital stock is a function of certain exogenous variables including: level of income, education and nutritional status, access to healthcare systems, material standard of living, health care spending (public spending and out-ofpocket spending), as well as, the incidence and/or prevalence of diseases, such as, COVID-19 (United Nations, 1988; Hill, A., 1987; Hobcroft, et al., 1984 and Dixon et al., 2001). Consequently, we rely on the works of Dixon et al., (2001) which postulated a model for health capital stock $\left(x_{t}\right)$ as follows:

$x_{t}=\left(w_{t}, m_{t}, d_{t}\right)$

Where $w_{t}$ measures material standard of living, $m_{t}$ is health care provision per capita, $d_{t}$ is the prevalence of diseases, such as, COVID-19. As a proxy for health capital, a number of studies adopted life expectancy (Refer to Murray and Chen, 1992; Murray and Lopez, 1997; Bloom et al., 2004 and Arrow et al., 2014, for a review of the empirical literature). In line with the extant literature, we employ life expectancy $\left(L_{t}\right)$ as a proxy for health capital. Hence, Eq. (36) becomes: $L_{t}=\left(w_{t}, m_{t}, d_{t}\right)$

Eq. (37) shows that there is unidirectional causality between life expectancy and its supposed determinants (material standard of living, health care provision per capita and prevalence of 
disease). To this end, we therefore ask an important question: Are feedback effects possible, most especially, between the prevalence of COVID-19 disease and life expectancy?

Regarding the key factors driving the rapid spread of coronavirus, the existing epidemiological studies have identified, among others, age, medical technology, health system capacity, public healthcare expenditure, access to healthcare system and climatic factors as major causative factors (Zhong et al., 2020; Pan et al., 2020; Barnett-Howell and Mobarak, 2020 and Ludvigsson, 2020). In addition, some authors including: Andrew et al., (2020), Didac (2020), Abdul et al., (2020), Nocolas, et al., (2020) and Sultan (2020) have revealed that COVID-19 disease to be highly prevalent among the elderly. By implication, countries with higher life expectancy would have larger number of victims among the adult population than other segments of the population (young children and the workforce). In fact, our preliminary findings as mentioned earlier in this paper (Refer to Section 1) showed that countries with the highest number of cases are mostly advanced countries, with higher life expectancy rates when compared to emerging and developing economies, such as African countries, with relatively lower life expectancy rates.

As a result of the forgoing discussion, we re-specify Eq. (37) as:

$D_{t}=\left(w_{t}, m_{t}, \mathrm{~L} t\right)$

Where $D_{t}$ implies the prevalence of COVID-19 while other variables maintain their previous definitions.

\subsection{Methodology and Data Issues}

\subsubsection{Estimation Procedure}

As mentioned in the preceding section, the empirical model for this study hinges on the reducedform health capital model, through which we established the relationship between disease prevalence and certain determining factors. In estimating the cross-sectional data, we would account for possible cross-sectional dependence due to proximity of countries across regions/continents, simultaneity and also endogeneity problems that could lead to bias regression that may arise between the variables of interest. To achieve this objective, the quantile regression approach was employed. As originally proposed by Koenker and Bassett (1978), quantile regression provides estimates of the linear relationship between explanatory variables and a specified quantile of the dependent variable. One important special case of quantile regression is the least absolute deviations (LAD) estimator, which corresponds to fitting the conditional median of the response variable.

A typical cross-sectional quantile regression can be specified as:

$y_{i}=x_{i}^{\prime} \beta_{\tau}+\varepsilon_{i}$ and Quant $_{\tau}\left(y_{i} / x_{i}\right)=x_{i}^{\prime} \beta_{\tau}$

Where $y_{i}$ is the response variable (prevalence of COVID-19 in this case); $x_{i}$ is a vector of explanatory variables (which stand for common and region-specific socio-economic variables in this case); $\beta_{i}$ is a vector of parameters to be estimated; $\varepsilon_{i}$ is a vector of disturbance terms; Quant $_{\tau}\left(y_{i} / x_{i}\right)$ identifies the $\tau^{\text {th }}$ conditional quantile of $y$ given $x$. 


\subsubsection{Measurement of Data and Sources}

The scope of this study covers countries of the world with confirmed cases of COVID-19 as at $30^{\text {th }}$ June, 2020. The choice of countries included was premised on data availability ${ }^{2}$. We measure COVID-19 prevalence as the ratio of confirmed cases as at as at $30^{\text {th }}$ June 2020 to population size as at 2017 for the counties in our sample set. We annualize this indicator by multiplying the computed COVID-19 prevalence rate by 12 months so as to align with the annual frequency of other variables utilized in this study. We classify the probable underlying causes of coronavirus pandemic into common and region-specific socio-economic characteristics. Consequently, the common features that are peculiar to all countries include life expectancy, population within the age bracket of ages 65 and above (\% of total population) and current health expenditure (\% of GDP). These data were obtained and compiled from the World Bank's World Development Indicator (WDI, 2019), while the data on confirmed cases of coronavirus were obtained from the World Health Organization (WHO) Situational Report on COVID-19 cases for June 2020.

We rely on epidemiological perspectives to argue for reverse causality from life expectancy to the prevalence of COVID-19 pandemic. Besides, other factors including number of aged persons and responsiveness of healthcare systems have been identified from the extant literature (see, for instance, Barnett-Howell and Mobarak, 2020; Meo, et al., 2020; Qasim, et al., 2020 and Robone, et al., 2011). It has been estimated that approximately $80 \%$ of COVID-19 fatalities are attributed to people are above 60 years of age (AFSS, 2020). Similarly, countries with robust and quality healthcare facilities are more likely to tame the spread of viral infection compared to countries with poor healthcare facilities. Robone, et al., (2011) offered an empirical evidence of a positive relationship between health care spending per capita and the responsiveness of healthcare system. Also obtained from WDI (2019) are data on region-specific socio-economic characteristics, whose selection is justified on a continent-by-continent basis as follows.

\section{AFRICA}

We identify acute healthcare system inadequacy as one of the age-long and structural challenges facing African countries. The continent's healthcare system is faced with key constraints, such as, low ratio of health professionals and hospital beds to population, inadequate health insurance coverage and ill-equipped medical-centers, among others (World Bank, 2016; UNECA, 2020). In Africa, access to health care services are generally low due to poor financial protection against health risks. Although total health expenditure has grown rapidly in the last two decades, the increase has been driven predominantly by out-of-pocket health spending of households (World Bank, 2016). Based on the data obtained from WDI (2019), we estimated that $67 \%$ of African countries had a ratio of out-of-pocket health spending to government health expenditure to be greater than one-to-one, with some outlier countries, such as, Nigeria and Guinea-Bissau posting higher ratios at 5:1 and 9:1 respectively. This shows that the burden of health care spending in Africa rests substantially on households with limited or no access to healthcare insurance. We, therefore, employ the out-of-pocket spending on healthcare as key underlying factor driving coronavirus spread in Africa.

\footnotetext{
${ }^{2}$ Countries were selected from four continents as follows: Africa (44), America (22), Asia (36) and Europe (41). Refer
} to the Appendix for the list of countries under each category. 


\section{ASIA}

The COVID-19 virus originated from China which is located in the continent of Asia. A possible factor that can fester the spread of the virus in this continent is geographical proximity to China. We hypothesize that surrounding countries with close proximity to the epicenter of the COVID19 virus will largely be influenced by the spread of the virus. According to Pedersen and Davies (2010), close geographical relations increase the likelihood of wider contraction rates and create an opportunity for transmission. Here, we employ the distance in kilometers from the Capital of China (Beijing) to the rest of Capital Cities of other countries in Asia (data obtained from CEPII database, retrievable via: http://www.cepii.fr/CEPII/en/bdd modele/inscription.asp?id=6 as a proxy variable to capture the role of geographical proximity in the spread of coronavirus. This is also well established in the recent outbreak of the second wave of COVID-19 in Beijing and neighbouring countries, such as, India.

\section{AMERICA}

The American continent is the world's topmost immigrant destination. It hosts about 51 million immigrants, accounting for $19 \%$ of global immigration, with the United States being the largest recipients of international citizens (United Nations, 2019). Alluding to the findings of Saker, et al., (2004), mass migration influences the spread of infectious diseases by bringing people into close contact with vectors, microbes and immunological makeup. Similarly, Wilson (1995) noted that human migration is a long time source of epidemic. A cursory look at net migration statistics, the US, Germany, Turkey, UK and Canada ranked the top five host countries for immigrants in 2017 (WDI, 2019). Remarkably, they also ranked among the countries with higher number of confirmed COVID-19 cases (see, WHO, 2020b, c, d \& e). Furthermore, given the fact that the first cases of coronavirus transmitted from China to the rest of the world, we can further test the hypothesis that "high immigration areas are likely to record greater number of foreigners' induced viral infections relative to countries with low recipients of immigrants. For instance, the first case of coronavirus in Canada was imported by a returnee from the Wuhan City of China. We, therefore, employ net migration - the difference between immigration and emigration - as a proxy variable to account for the role of migration in the spread of coronavirus worldwide.

\section{EUROPE}

Europe is the most popular continent for travelers and tourists. The continent ranks the world's topmost tourist destination due to its rich history and heritage, favorable climatic condition, architecture and developed transport infrastructure ${ }^{3}$. According to World Tourism organization (2018), Europe played host to $51 \%$ of the number of international tourist arrivals - equivalent to 714.51 million tourists. The continent also ranked the highest recipient of tourism revenue at $40 \%$ of total receipts in 2019 (UNWTO, 2019). In line with the assertion of Wilson (1995), countries with higher travel records are more likely to experience a rapid spread of COVID-19 pandemic. We therefore identify the number of international arrivals as the major socio-economic condition that is peculiar to Europe.

\footnotetext{
${ }^{3}$ See worldatlas.com
} 


\section{Empirical Analysis and Discussion of Results}

\subsection{Descriptive Analysis}

The summary statistics on all variables across the four continents captured in this study are summarized in Table 1. We observe that the American continent has the highest average prevalence rate of COVID-19 at 3.7\%, followed by Europe (3.3\%) and Asia (2\%), with Africa having the lowest prevalent rate at $0.5 \%$. This truly reflects the hierarchy of countries in terms of the number of confirmed cases globally with the United States, Brazil, India and Russia topping the list. Europe emerges the world's largest continent of adult population with an average share of $16.5 \%$ of total population. This is followed closely by the US with an average adult population share of $9.5 \%$ and Asia with an average share of $6.2 \%$ in their respective total population figures. Again, Africa domiciles the world's lowest share of adult population at $3.6 \%$ of total population on the continent. This ultimately buttresses the findings that Africa is home to the world's youngest population ${ }^{4}$. In terms of share of health sector expenditure in GDP, we observe that Europe and America outperform the other two continents (Asia and Africa) on the average. In addition, statistics show that Europe has the highest average life expectancy rate at 78 years, followed by Asia (74 years) and America ( 73 years). On the other hand, Africa has the world's lowest average life expectancy rate of 64 years. These findings are symmetrical to the adult population statistics and reflect the variation in health care spending across the four continents. In terms of regionspecific factors, average out-of-pocket spending on health care in Africa is $35 \%$ of total health care financing in the continent. Similarly, net migration, distance of Asian countries from Beijing (China's capital city) and international arrivals averaged 113,639 migrants, 4,911.2 kilometres and $15,800,000$ tourists in America, Asia and Europe, respectively. Information on other summary statistics (standard deviation, minimum and maximum values) show some degrees of variation across the four continents. To this end, we take up a further investigation into the factors - common and/or region-specific - that are driving COVID-19 prevalence in Africa, America, Asia and Europe in the rest of this section.

Table 1: Summary Statistics

\begin{tabular}{cccccc}
\hline & Obs. & Mean & Std. Deviation & Minimum & Maximum \\
\hline \multicolumn{6}{c}{ Common Factors } \\
\hline \multicolumn{6}{c}{ prev_12 } \\
\hline AFRICA & 44 & 0.535 & 0.791 & 0.111 & 3.135 \\
AMERICA & 22 & 3.676 & 4.559 & 1.181 & 17.061 \\
ASIA & 36 & 2.042 & 4.461 & 0.003 & 24.338 \\
EUROPE & 41 & 3.290 & 2.710 & 0.299 & 10.408 \\
\hline \multicolumn{6}{c}{ ad_pop } \\
\hline AFRICA & 44 & 3.602 & 1.809 & 1.920 & 10.952 \\
AMERICA & 22 & 9.509 & 4.411 & 4.561 & 18.722 \\
ASIA & 36 & 6.241 & 4.806 & 1.035 & 27.109 \\
EUROPE & 41 & 16.536 & 4.388 & 4.413 & 22.499 \\
\hline \multicolumn{6}{c}{$h e_{-g d p}$} \\
AFRICA & 44 & 5.569 & 2.089 & 2.781 & 13.421 \\
AMERICA & 22 & 7.632 & 2.939 & 1.181 & 17.061
\end{tabular}

${ }^{4}$ WEF (2017). "The Future of Jobs and Skills in Africa: Preparing the Region for the Fourth Industrial Revolution". An Executive Briefing of the World Economic Forum. 


\begin{tabular}{cccccc} 
ASIA & 36 & 5.419 & 2.543 & 2.274 & 11.777 \\
EUROPE & 41 & 7.944 & 2.111 & 3.125 & 12.346 \\
\hline \multicolumn{6}{c}{ lfe } \\
\hline AFRICA & 44 & 63.545 & 6.419 & 52.24 & 76.499 \\
AMERICA & 22 & 73.322 & 3.927 & 61.6 & 79.3 \\
ASIA & 36 & 74.356 & 4.881 & 64.13 & 84.099 \\
EUROPE & 41 & 78.403 & 3.901 & 71.2 & 83.551 \\
\hline \multicolumn{5}{c}{ Region-Specific Factor } \\
\hline AFRICA: oope & 44 & 35.055 & 18.912 & 2.993 & 77.225 \\
AMERICA: $n$ migrate & 22 & 113,639 & $1,303,750$ & $-3,266,243$ & $4,774,029$ \\
ASIA: distance & 36 & $4,911.283$ & $2,646.841$ & 955.651 & $14,937.48$ \\
EUROPE: arrivals & 41 & $15,800,000$ & $20,300,000$ & 145,000 & $86,800,000$ \\
\hline
\end{tabular}

\subsection{The Regression Results}

Here, we present the quantile regression results on the determinants of coronavirus prevalence in the four continents under study. We utilized three quantile dimensions including the first quantile (33\%), the second quantile (67\%) and the last quantile (99\%) of COVID-19 prevalence distributions across the four continents. This is informed by the need to account for observed differences in socio-economic characteristics across countries within each continent.

\subsubsection{Quantile Regression Estimates of COVID-19 Prevalence in Africa}

Our results show that at the lowest quantile (that is, 33\% of data distribution), out-of-pocket spending and life expectancy are significant influencers of coronavirus prevalence in Africa (see Table 2). However, considering the highest quantile (99\%), socio-economic factors including the level of adult population, health care spending, out-of-pocket spending on healthcare and life expectancy appear as the significant determinants of COVID-19 prevalence on the continent. We are able to obtain evidence for the fact that African countries on the highest scale of adult population distribution would exhibit higher prevalence of the pandemic compared with the countries on the lowest scale of the distribution. This confirms the findings of previous studies that aged persons has a very high risk of contracting and dying of the viral infection ${ }^{5}$. Our results also show that higher spending on the health sector is significantly and negatively related to coronavirus prevalence. Meanwhile, the impact of out-of-pocket spending on healthcare differs across quantiles, with the lowest quantile showing a higher risk of contagion while the highest quantile indicates a lower level of contagion ${ }^{6}$. This implies that regional efforts towards increasing public expenditure on the health sector would play a vital role in mitigating the spread of coronavirus across Africa. In addition, we also observe the significant role of higher life expectancy in fueling the spread of COVID-19, which is more pronounced, particularly, at the highest quantile. Following the coefficient of determination criterion, estimates based on the highest quantile show a more adequate sensitivity analysis of coronavirus prevalence to key socio-economic indicators in Africa.

\footnotetext{
${ }^{5}$ See, for instance, Barnett-Howell and Mobarak (2020), Ludvigsson (2020), Meo, et al., (2020),

${ }^{6}$ See, for instance, Qasim, et al., (2020).
} 
Table 2: Quantile Regression Estimates of COVID-19 Prevalence in Africa

\begin{tabular}{cccc}
\hline & prev_12_Q33 & prev_12_Q67 & prev_12_Q99 \\
\hline ad_pop & 0.0084 & 0.1469 & $0.6273 * * *$ \\
& $(0.123)$ & $(0.1425)$ & $(0.0206)$ \\
he_gdp & 0.0069 & -0.0077 & $-0.2044 * * *$ \\
& $(0.1133)$ & $(0.1006)$ & $(0.0124)$ \\
oope & $0.0028 * *$ & 0.0064 & $-0.010 * * *$ \\
& $(0.0011)$ & $(0.0131)$ & $(0.0015)$ \\
llfe & $0.5461 * *$ & -0.6567 & $2.6191 * * *$ \\
& $(0.2312)$ & $(2.895)$ & $(0.36667)$ \\
constant & $-2.3006 * *$ & 2.4663 & $-9.2599 * * *$ \\
& $(0.9722)$ & $(12.0184)$ & $(1.5264)$ \\
\hline$R^{2}$ & 0.0543 & 0.0631 & 0.2939
\end{tabular}

Note: $* * *, * *$ indicate the statistical significance of coefficients at $1 \%$ and $5 \%$ respectively; the values in parentheses are standard errors.

\subsubsection{Quantile Regression Estimates of COVID-19 Prevalence in America}

We observe that at the lowest quantile (that is, 33\% of data distribution), net migration is the only significant driver of coronavirus prevalence in America (see Table 3). Meanwhile, considering the highest quantile (99\% of data distribution), socio-economic factors including the level of adult population, life expectancy, health care spending and net migration emerge as the significant influencers of COVID-19 prevalence on the continent. We offer evidence for the fact that American countries on the highest scale of adult population distribution would exhibit higher prevalence of the pandemic compared with other countries on the lowest scale. The same evidence was offered for life expectancy. This also affirms the findings of previous studies that aged has a very high risk of contracting and dying of the viral infection ${ }^{7}$. Our results also reflect that higher spending on the health sector is significantly and negatively related to coronavirus prevalence on the American continent. Though, as expected, net migration is a positive influencer of coronavirus spread, its magnitude of impact is the lowest. Nonetheless, this result indicates the increasing vulnerability of the American continent on the backdrop of its position as the world's largest net migrant region. Based on the coefficient of determination criterion, estimates from the highest quantile regression show a more adequate sensitivity analysis of coronavirus prevalence to key socio-economic indicators in America.

Table 3: Quantile Regression Estimates of COVID-19 Prevalence in America

\begin{tabular}{cccc}
\hline & prev_12_Q33 & prev_12_Q67 & prev_12_Q99 \\
\hline ad_pop & 0.0153 & -0.2682 & $1.9472 * * *$ \\
& $(0.2497)$ & $(0.5216)$ & $\left(5.33 \mathrm{e}^{-08}\right)$ \\
llfe & -0.2101 & 15.6229 & $15.2189 * * *$ \\
& $(13.7581)$ & $(50.8949)$ & $\left(3.02 \mathrm{e}^{-06}\right)$ \\
he_gdp & -0.727 & -0.8119 & $-0.0741 * * *$ \\
& $(0.5231)$ & $(2.083)$ & $\left(1.14 \mathrm{e}^{-07}\right)$ \\
n_migrate & $3.07 \mathrm{e}^{-06 * *}$ & $3.12 \mathrm{e}^{-06}$ & $2.47 \mathrm{e}^{-06 * * *}$ \\
& $\left(1.1 \mathrm{e}^{-06}\right)$ & $\left(4.79 \mathrm{e}^{-06}\right)$ & $\left(2.39 \mathrm{e}^{-13}\right)$ \\
constant & 7.8095 & -55.3699 & $-70.4618^{* * *}$ \\
\hline
\end{tabular}

${ }^{7}$ See, for instance, Andrew et al., (2020), Didac (2020), Abdul et al., (2020), Nocolas, et al., (2020) and Sultan (2020). 


\begin{tabular}{cccc}
\hline & $(59.2013)$ & $(220.3959)$ & $\left(2.39 \mathrm{e}^{-13}\right)$ \\
\hline$R^{2}$ & 0.1501 & 0.2077 & 0.3383 \\
\hline
\end{tabular}

Note: $* * *, * *$ indicate the statistical significance of coefficients at $1 \%$ and $5 \%$ respectively; the values in parentheses are standard errors.

\subsubsection{Quantile Regression Estimates of COVID-19 Prevalence in Asia}

Our results indicate that at the lowest quantile and middle quantiles, adult population and life expectancy are the significant influencers of coronavirus prevalence in Asia (see Table 4). Meanwhile, considering the highest quantile ( $99 \%$ of data distribution), in addition to the aforementioned factors, health care spending and the distance of Asian countries from China's capital - Beijing - are also significant drivers of COVID-19 spread across the continent. In contrast with other Africa and America, adult population exerts a negative influence on prevalence rate in Asia in a descending order from the lowest quantile to the highest quantile. This reflects the significant breakthrough of the coronavirus origin and the most populous country in world - China - in curtailing the spread of the virus since it became a pandemic in March 2020. This could be said to have helped to reduce drastically the prevalence rate in the Asian continent as reflected in its third position (see Table 1). With the exception of life expectancy, other socio-economic indicators including healthcare spending and distance show an entirely different signs relative to the a priori expectations. This does not however downgrade the relative importance of proximity effect and lower health care expenditure in driving the overall spread of coronavirus on the Asian continent. Meanwhile, the most significant factor is life expectancy, where COVID-19 prevalence has the highest sensitivity relative to the other three continents. This could be attributed to issues around demography as Asia remains the world's most populous continent. Following the coefficient of determination criterion, estimates from the highest quantile regression show a more adequate sensitivity analysis of coronavirus prevalence to key socio-economic indicators in Asia.

Table 4: Quantile Regression Estimates of COVID-19 Prevalence in Asia

\begin{tabular}{cccc}
\hline & prev_12_Q33 & prev_12_Q67 & prev_12_Q99 \\
\hline$a d \_p o p$ & $-0.0566^{* * *}$ & $-0.2072^{*}$ & $-1.0882^{* * * *}$ \\
& $(0.0095)$ & $(0.1152)$ & $(0.0205)$ \\
$h e_{-} g d p$ & 0.0172 & 0.1284 & $0.2848^{* * *}$ \\
& $(0.0152)$ & $(0.1602)$ & $(0.0321)$ \\
llfe & $3.9369^{* * *}$ & $20.0815^{* *}$ & $107.0914^{* * *}$ \\
& $(0.5822)$ & $(8.839)$ & $(1.3473)$ \\
ldistance & 0.0228 & 0.8517 & $3.4955^{* * *}$ \\
& $(0.0757)$ & $(0.7854)$ & $(0.1746)$ \\
constant & $-16.6326^{* * *}$ & $-91.1431^{* *}$ & $-474.8195^{* * *}$ \\
& $(2.3843)$ & $(37.7275)$ & $(5.4457)$ \\
\hline$R^{2}$ & 0.0467 & 0.2165 & 0.6273
\end{tabular}

Note: $* * *, * *, *$ indicate the statistical significance of coefficients at $1 \%, 5 \%$ and $10 \%$ respectively; the values in parentheses are standard errors.

\subsubsection{Quantile Regression Estimates of COVID-19 Prevalence in Europe}

We observe that it is only at the upper quantile (99\% of data distribution) that socio-economic factors including adult population, health expenditure, life expectancy and international arrivals are significant drivers of COVID-19 spread across Europe. In contrast with other continents, all variables have associated coefficients that contradict the a priori expectations. Meanwhile, the 
impact of rising adult population size on prevalence rate declines at the upper quantile relative to the middle quantile. Similarly, to suggest the need for higher health spending, the prevalence of COVID-19 to health spending declined between the middle and upper quantiles. Though the impact coefficients associated with life expectancy at the lower and middle quantiles are not statistically significant, the mere fact that these coefficients are positive suggests the role of higher life expectancy rate in driving up the spread of the coronavirus pandemic. The same explanation goes for the level of international arrivals where the impact coefficients at particularly the lower and middle quantiles indicate the role of tourist influx in magnifying the prevalence rate in Europe. This informed the decision of many European countries to impose stiff restrictions on travelers until date in replacement for travel ban previously imposed across countries. Following the coefficient of determination criterion, estimates from the highest quantile regression and to some extent from the middle quantile constitute a more adequate sensitivity analysis of coronavirus prevalence to key socio-economic indicators in Europe.

Table 5: Quantile Regression Estimates of COVID-19 Prevalence in Europe

\begin{tabular}{cccc}
\hline & prev_12_Q33 & prev_12_Q67 & prev_12_Q99 \\
\hline ad_pop & -0.1194 & -0.3013 & $-0.154 * * *$ \\
& $(0.0828)$ & $(0.1938)$ & $(0.0165)$ \\
$h e \_g d p$ & 0.2302 & 0.3345 & $0.2489 * * *$ \\
& $(0.1649)$ & $(0.5468)$ & $(0.0292)$ \\
llfe & 5.2007 & 32.2612 & $-3.6836^{* *}$ \\
& $(7.9429)$ & $(23.1741)$ & $(1.3789)$ \\
larrivals & 0.1826 & 0.1489 & $-0.4971 * * *$ \\
& $(0.1993)$ & $(0.7046)$ & $(0.0417)$ \\
constant & -23.7269 & -136.6092 & $32.4995 * * *$ \\
& $(32.2948)$ & $(95.2082)$ & $(5.7377)$ \\
\hline$R^{2}$ & 0.1385 & 0.1647 & 0.336
\end{tabular}

Note: $* * *, * *$ indicate the statistical significance of coefficients at $1 \%$ and $5 \%$ respectively; the values in parentheses are standard errors.

\section{Concluding Remarks}

In this study, a number of contributions were made to the literature on the prevalence of COVID19. Most notably, in addition to identifying the common factors driving the spread of coronavirus pandemic across all regions, we captured region-specific factors in our investigation. We utilized the quantile regression approach within a cross-section of 153 countries drawn from four continents including Africa, America, Asia and Europe. Succinctly, our major findings are as follows; One, common factors (life expectancy, level of adult population and health expectancy) significantly influenced the prevalence of COVID-19 in all continents. Two, African-specific factor - out-of-pocket spending - shows a high risk of contagion at the lowest quantile. Three, in the American continent, both at the lowest and highest quantiles, net migration positively and significantly influenced the spread of coronavirus pandemic. Four, in the continent of Asia, life expectancy is the most significant factor that drives the COVID-19 prevalence. Five, for Europe, the number of international tourist arrivals positively influenced coronavirus spread, particularly, at the highest quantile.

In view of the foregoing, our findings birthed the following policy recommendations. First, in Africa, much priorities should be directed at making provisions for a universal health insurance 
coverage. This would ultimately reduce out-of-pocket spending on healthcare and guarantee improved access to healthcare facilities. We expect this policy initiative to reduce the spread of infectious diseases including COVID-19 in the continent. Second, for America and Europe, which host large number of immigrants and international tourists, efforts should be intensified towards limiting non-essential travels. Also, health checks should be beefed up for entrants into these continents in order to mitigate the spread of coronavirus. Finally, for Asia, the most important factor influencing the spread of COVID-19 is higher life expectancy rates. Hence, decision makers should implement social and health specific policies targeted towards the aged, including restricting their presence in social gatherings and making sure they observe social distancing rule. This also applies to other age groups since current realities show that no individual (young or aged) is immune to contracting the viral infection. 


\section{References}

Adhikari, S.P., Meng, S., Wu, Y., Mao, Y., Ye, R., Wang, Q., Sun, C., Sylvia, S., Rozelle, S., Raat, H. and Zhou, H. (2020). Epidemiology, causes, Clinical Manifestation and Diagnosis, Prevention and Control of Coronavirus Disease (COVID-19) During the Early Outbreak Period: a Scoping Review, Scoping Review - Infectious Diseases of Poverty, Open Access, https://doi.org/10.1186/s40249-020-00646-x

Africa Center for Strategic Studies (ACSS), (2020). Mapping Risk Factors for the Spread of COVID-19 in Africa.

Alwaeli, A. A., Al-Sharifi, K. O., \& Al-Sudani, M. M. (2020). Spatial and Temporal Analysis of Coronavirus (Covid 19) In Iraq and Its Relationship to Temperature Averages. East African Scholars Journal of Education, Humanities and Literature, 2(5), 169-178.

Arrow, K., Dasgupta, P., \& Mumford, K. (2014). Health Capital. Inclusive Wealth Report: Measuring Progress Towards Sustainability -Delhi: UNDP\&UNEP, 123-134.

Barnett-Howell, Z., \& Mobarak, A. M. (2020). The Benefits and Costs of Social Distancing in Rich and Poor Countries. arXiv preprint arXiv:2004.04867.

Bloom, D. E., and Canning, D. (2004). Epidemics and Economics. Interactions between Global Change and Human Health. Scripta Varia, 106, 304-331.

Brenton, P., \& Chemutai, V. (2020). Trade Responses to the COVID-19 Crisis in Africa. Trade and COVID-19 Guidance Notes, Equitable Growth, Finance and Institution, World Bank Publications. https://doi.org/10.1596/33548

CDC. HAN Archive (2020) - 00426. Health Alert Network (HAN). https://emergency.cdc.gov/han/han00426.asp. Published February 11, 2020. Accessed March 19, 2020 .

Chavez, S., Long, B., Koyfman, A. and Liang, S.Y. (2020). Coronavirus Disease (COVID-19): A Primer for Emergency Physicians, American Journal of Emergency Medicine, https://doi.org/10.1016/j.ajem.2020.03.036

Clark A., Jit, M., Warren-Gash, C., Guthrie, B., Wang, H. W., Mercer, W. S., Sanderson, C, McKee, M., Troeger, C., Ong, K. I., Checchi, F., Perel, P., Joseph, S., Gibbs, H. P., Banerjee, A., and Eggo, R. M. (2020). How many are at Increased Risk of Severe COVID-19 Disease? Rapid Global, Regional and National Estimates for 2020. MedRxiv Preprint.

Ding, Y., Luo, S., Zheng, X., Ling, P., Yue, T., Liu, Z., and Weng, J. (2020). Association between Population, Migration and Epidemic Control of Coronavirus Diseases 2019. Science China Life Sciences, 63(6), 1-4.

Dixon, S., McDonald, S., and Roberts, J. (2001). HIV/AIDS and Development in Africa. Journal of International Development, 13(4), 381-389. 
Funk, S. (2010). Modelling the Influence of Human Behavior on the Spread of Infectious Diseases: Journal of the Royal Society Interface, 7(50), 1247-1256.

Gémes, K., Talbäck, M., Modig, K., Ahlbom, A., Berglund, A., Feychting, M. and Matthews, A. A. (2020). Burden and Prevalence of Prognostic Factors for Severe COVID-19 in Sweden. European Journal of Epidemiology, 1(1), 1-9.

Hafeez, A., Ahmad, S., Siddqui, S. A., Ahmad, M., \& Mishra, S. (2019). A Review of COVID-19 (Coronavirus Disease-2019) Diagnosis, Treatments and Prevention. EMJO, 4(2), 116-125.

Harper, S., and Lynch, J. (2006). Accounting for Changes in Health Inequalities in Smoking and Obesity in the United States, 1969-2000. In Annual Meeting of the Population Association of America, March, Los Angeles, CA.

Hill, A. (1987). Trends in Childhood Mortality in Sub-Saharan Mainland Africa. Paper Presented at the International Union for the Scientific Study of Population. Seminar on Mortality and Society in Sub-Saharan Africa, 37-70.

Hobcroft, J., McDonald, J., Rutsein, S., (1984). Socio-economic Factors in Infant and Child Mortality: A Cross-national Comparison. Population Studies, 38(2), 193-223.

Howell and Mobarak (2020) Should Low-Income Countries Impose the Same Social Distancing Guidelines as Europe and North America to Halt the Spread of COVID-19: YALE Research Innovative on Innovation and Scale, Yale School of Management Science.

International Monetary Fund (IMF) (2020). World Economic Outlook, June 2020.

Jindal, V.K. (2020). COVID-19 Primary and Secondary Infection as Order Parameter - a Unifying Global Model. A Researcg Paper from the Department of Bio and Nano Sciences, Guru Jambheshwar University Hisar -India.

Jonas, O. (2013). Pandemic Risk. World Development Report.

Karatayev, V. A., Anand, M., Bauch, C. T. (2020). The Far side of the COVID-19 Epidemic curve: Local re-openings based on globally coordinated triggers may work best. MedRxiv. https://doi.org/10.1101/2020.05.10.20097485

Koenker, Roger and Gilbert Bassett, Jr. (1978). "Regression Quantiles," Econometrica, 46(1), 3350 .

Khan, A., Islam, T., Usman, S., Zaman, Y. K., Shoukry, A. M., Sharkawy, A. M., Gani, S., Aamir, A., Hishan, S. S. (2019). The Impact of Financial Development Indicators on Natural Resource Markets: Evidence from Two-step GMM Estimator. Journal of Resources Policy, 62, 240-255.

Knowles, S., and Owen, D. (1995). Health Capital and Cross-country Variation in Income per Capita in the Mankiw-Romer-Weil Model. Economics Letters, 48(1), 99-106. 
Lin, Q., Zhao, S., Gao, D., Lou, Y., Yang, S., Musa, S.S., Wang, M.H., Cai, Y., Wang, W., Yang, L. and He, D. (2020). A Conceptual Model for the Coronavirus Disease 2019 (COVID-19) Outbreak in Wuhan, China with Individual Reaction and Governmental Action. International Journal of Infectious Diseases, 93, 211 - 216. https://doi.org/10.1016/j.ijid.2020.02.058

Ludvigsson, J. F. (2020). Systematic Review of COVID-19 in Children Shows Milder Cases and a Better Prognosis than Adults. Acta Paediatrica, 109(6), 1088-1095.

Mankiw, N. G., Romer, D., and Weil, N. D. (1992). A Contribution to the Empirics of Economic Growth. The Quarterly Journal of Economics, Oxford University Press, 102(2), 407-437.

Mao, L. and Yang, Y. (2012). Coupling Infectious Diseases, Human Preventive Behavior, and Networks - A Conceptual Framework for Epidemic Modeling, Social Science and Medicine, 74, 167-175. doi:10.1016/j.socscimed.2011.10.012

McIntosh K. (2020) In: Hirsch M, Bloom A, editors. Coronavirus disease 2019 (COVID-19). Date; February 2020. https://www.uptodate.com/contents/coronavirus-disease-2019-covid-19/print

McKibbin and Fernando (2020) The Global Macroeconomic Impacts of COVID-19: Seven Scenarios. CAMA Working Paper 19/2020.

Meo, S. A., Al-Khlaiwi, T., Usmani, A. M., Meo, A. S., Klonoff, D. C., \& Hoang, T. D. (2020). Biological and Epidemiological Trends in the Prevalence and Mortality Due to Outbreaks of Novel Coronavirus (COVID-19). Journal of King Saud University - Science. https://doi.org/10.1016/j.jksus.2020.04.004

Murray, C. J. L., and Chen, L. C. (1992). Understanding morbidity change. Population and Development Review, 18, 481-503.

Murray, C. J. L., and Lopez, A. D. (1997). Regional Patterns of Disability-free Life Expectancy and Disability Adjusted Life Expectancy: Global Burden of Disease Study. Lancet, 349, 13471352.

Muurlink O. T., and Taylor-Robinson, W. A. (2020). COVID-19: Cultural Predictors of Gender Differences in Global Prevalence Patterns. Journal Frontiers in Public Health, 8(174), 1-2 10.3389/fpubh.2020.00174

Ogundokun, R.O., Lukman, A.F., Kibria, G.B.M., Awotunde, J.B. and Aladeitan, B.B. (2020). "Predictive modelling of COVID-19 confirmed cases in Nigeria". Infectious Disease Modelling, 5: 543-548.

Ozili and Arun (2020) Spillover of COVID-19: Impact on the Global Economy: Article in SSRN Electronic Journal · November 2020 DOI: 10.2139/ssrn.3562570

Page, L. M. (2020) Viruses from Animals. New Scientist, 245(3287), 10. 
Pan, A., Liu, L., Wang, C., Guo, H., Hao, X., Wang, Q., \& Wei, S. (2020). Association of Public Health Interventions with the Epidemiology of the COVID-19 Outbreak in Wuhan, China. Jama, 323(19), 1915-1923.

Pedersen, B. A. and Davies, J. T. (2010). Cross Species Pathogen Transmission and Disease Emergence in Primates. EcoHealth, 6(4), 496-508.

Qasim, M., Ahmad, W., Zhang, S., Yasir, M., Azhar, M. (2020). Data Model to Predict Prevalence of COVID-19 in Pakistan. MedRxiv Preprint.

Roberton, T., Carter, D. E., Chou, B. V., Stegmuller, R. A., Jackson, D. B., Tam, Y. SawadogoLewis, T. and Walker, N. (2020). Early Estimates of the Indirect Effects of the COVID-19 Pandemic on Maternal and Child Mortality in Low-Income and Middle-Income Countries: a Modelling Study. The Lancet Global Health, 8(7), 901-908.

Robone, S., Rice, N., and Smith, C. P. (2011). Health Systems' Responsiveness and Its Characteristics: A Cross-Country Comparative Analysis. Health Services Research, 46(6), 20792100 .

Saker, L., Lee, K., Cannito, B., Gilmore, A., and Campbell-Lendrum, D. (2004). Globalization and Infectious Disease: A Review of the Linkages. Social, Economic and Behavioral Research, TDR/STR/SEB/ST/04.2, World Health Organization.

Santesmasses, D., Castro, J. P., Zenin, A. A., Shindyapina, A. V., Gerashchenko, M. V., Zhang, B., \& Gladyshev, V. N. (2020). COVID-19 is an Emergent Disease of Aging. MedRxiv Preprint.

Shereen, M.A., Khan, S., Kazmi, A., Bashir, N. and Siddique, R. (2020). COVID-19 Infection: Origin, Transmission, and Characteristics of Human Coronaviruses. Journal of Advanced Research, 24, 91-98.

Silverstein, W.K., Stroud, L., Cleghorn, G. E., and Leis, J. A (2020). First Imported Cases of 2019 Novel Coronavirus in Canada, Presenting as Mild Pneumonia. The Lancet, 395(10225), 734

Surico, P. and Galeotti, A. (2020). The Economics of a Pandemic: The Case of COVID-19. London Business School, Wheeler Institute of Business and Development. London Business School. https://www.far.org.nz/assets/files/blog/files/3093ca6a-a676-568f-9e7c-5dc77c4e188f.pdf

Taboe, H. B., Salako, V. K., Ngonghala, N. C., and Kakai, G. R. (2020). Predicting COVID-19 Spread and Public Health Needs to Contain the Pandemic in West-Africa. MedRxiv (Preprint).

The World Tourism Organization (UNWTO). (2019). International Tourism Highlights, 2019 UNCTAD (2020). Global Trade Impact on Covid-19 Pandemic: Trade and Development Report, March 04, 2020.

United Nations Economic Commission for Africa (UNECA), (2020). COVID-19 in Africa: Protecting Lives and Economies. International Migration. UNECA Publications. 
United Nations, (1988). Mortality of Children Under age 5, World Estimates and Projections 1950-2025. New York Department of International Economic and Social Affairs, Population Studies No. 105.

Wang, J., Tang, K., Feng, K., Lin, X., Lv, W., Chen, K., and Wang, F. (2020). High Temperature and High Humidity Reduce the Transmission of COVID-19. Available at SSRN 3551767

WHO. Novel Coronavirus-China. (2020a). https://www.who.int/csr/don/12january-2020novelcoronavirus-china/en/. Accessed 1 Feb 2020.

Wilson, M. E. (1995). Travel and Emergence of Infectious diseases. Emerging Infectious Diseases. $1,39-46$.

World Health Organization. (2015). Tracking Universal Health Coverage: First Global Monitoring Report. World Health Organization.

World Bank Development Indicator (WDI) (2019). International Economics Department Development Group. The World Bank. Population Division. https://data.worldbank.org/

World Health Organization (2020b). Coronavirus disease 2019 (COVID-19) Situation Report 71: Data as Reported by National Authorities by 10:00 CET 31 March 2020.

World Health Organization (2020c). Coronavirus disease 2019 (COVID-19) Situation Report 101: Data as Reported by National Authorities at 10:00 CET 30 April 2020.

World Health Organization (2020d). Coronavirus disease 2019 (COVID-19) Situation Report 132: Data as Reported by National Authorities at 10:00 CET 31 May 2020.

World Health Organization (2020e). Coronavirus disease 2019 (COVID-19) Situation Report 162: Data as Reported by National Authorities at 10:00 CET 30 June 2020.

World Tourism Organization (UNWTO). (2018). International Tourist Highlights, 2019 Edition. Zhong, B. Li., Luo, W., Li, H. M., Zhang, Q. Q., Liu, X. G., Li, W. T., and Li, Y. (2020). Knowledge, Attitudes and Practices towards COVID-19 among Chinese Residents during the Rapid Rise Period of COVID-19 Outbreak: A Quick Online Cross-sectional Survey. International Journal of Biological Sciences, 16(10), 1745. 
Appendix: List of Sampled Countries across Four Continents

\begin{tabular}{|c|c|c|c|c|c|c|}
\hline \multicolumn{2}{|c|}{ Africa } & \multirow{2}{*}{$\begin{array}{l}\text { America } \\
\text { Argentina }\end{array}$} & \multicolumn{2}{|c|}{ Asia } & \multicolumn{2}{|c|}{ Europe } \\
\hline Algeria & Nigeria & & Afghanistan & Timor-leste & Armenia & Serbia \\
\hline Angola & $\begin{array}{l}\text { Rwanda } \\
\text { Sao Tome \& }\end{array}$ & & Armenia & UAE & Austria & Slovakia \\
\hline Benin & Principe & Canada & Bahrain & Uzbekistan & Azerbaijan & Slovenia \\
\hline Botswana & Senegal & Chile & Bangladesh & Vietnam & Belarus & Spain \\
\hline Burkina Faso & Seychelles & $\begin{array}{l}\text { Costa Rica } \\
\text { Dominican }\end{array}$ & $\begin{array}{l}\text { Bhutan } \\
\text { Brunei }\end{array}$ & & $\begin{array}{l}\text { Belgium } \\
\text { Bosnia \& }\end{array}$ & Sweden \\
\hline Burundi & Sierra Leone & Rep. & Durussalam & & Herzegovina & $\begin{array}{l}\text { Switzerland } \\
\text { United }\end{array}$ \\
\hline Cabo Verde & South Africa & Ecuador & Cambodia & & Croatia & Kingdom \\
\hline $\begin{array}{l}\text { Cameroon } \\
\text { Central }\end{array}$ & Rwanda & El Salvador & China & & Cyprus & Turkey \\
\hline African Rep. & Tanzania & Guatemara & India & & Czech Rep. & Ukraine \\
\hline Chad & Togo & Haiti & Indonesia & & Denmark & \\
\hline $\begin{array}{l}\text { Dem. Rep. of } \\
\text { Congo }\end{array}$ & Tunisia & Honduras & Iran & & Estonia & \\
\hline Rep. of Congo & Uganda & Jamaica & Iraq & & Finland & \\
\hline Cote d'Ivoire & Zambia & Mexico & Israel & & France & \\
\hline Egypt & & Nicaragua & Japan & & Georgia & \\
\hline Eswatini & & Panama & Jordan & & Germany & \\
\hline Ethiopia & & Paraguay & Kuwait & & Greece & \\
\hline Gabon & & Peru & Lao PDR & & Hungary & \\
\hline The Gambia & & Puerto Rico & Lebanon & & Iceland & \\
\hline Ghana & & United States & Malaysia & & Ireland & \\
\hline Guinea & & $\begin{array}{l}\text { Uruguay } \\
\text { US Virgin }\end{array}$ & Maldives & & Italy & \\
\hline Guinea-Bissau & & Islands & Mongolia & & Kazakhstan & \\
\hline Kenya & & Venezuela & Nepal & & Kyrgyzstan & \\
\hline Lesotho & & & Oman & & Latvia & \\
\hline Liberia & & & Pakistan & & Lithuania & \\
\hline Madagascar & & & Philippines & & Luxembourg & \\
\hline Malawi & & & $\begin{array}{l}\text { Qatar } \\
\text { Republic of }\end{array}$ & & Netherlands & \\
\hline Mali & & & Korea & & Norway & \\
\hline Mauritania & & & Saudi Arabia & & Poland & \\
\hline Mauritius & & & Singapore & & Portugal & \\
\hline Morocco & & & Sri Lanka & & $\begin{array}{l}\text { Rep. of } \\
\text { Moldova }\end{array}$ & \\
\hline Mozambique & & & Tajikistan & & Romania & \\
\hline Niger & & & Thailand & & Russia & \\
\hline
\end{tabular}

Note: Selection of countries across continents is strictly based on data availability. 